\title{
CALORIMETRY OF DEFORMED ALUMINUM REINFORCED WITH ALUMINA PARTICLES
}

\author{
M.B. Srichai*, D.C. Dunand and A. Mortensen \\ Department of Materials Science and Engineering, Massachusetts Institute of Technology, Cambridge, MA 02139, USA. \\ * currently at the Medical School, Johns Hopkins University, Baltimore, MD 21218, USA. \\ (Received November 1,1993 ) \\ (Revised February 25, 1994)

\section{Introduction}

It is known that stiff, elastic ceramic reinforcements used in metal matrix composites can strongly influence dislocation creation, annihilation and motion within the matrix (see for example the articles of Viewpoint 15 of this Journal (1)). In particular, mechanical interaction between reinforcement and matrix may result in dislocation densities in reinforced metals that exceed greatly those found in the unreinforced matrix metal, processed and strained analogously to the composite (2-5). Dislocation densities in metals are generally measured using transmission electron microscopy; however several precautions are required with this technique (6), which are exacerbated in the case of metal matrix composites because of thermal strain mismatch between matrix and reinforcement $(4,5)$. Differential scanning calorimetry offers an alternative method of measuring dislocation densities in deformed metals, which has its limitations (dislocation densities must be relatively high, and the matrix must be highly pure and must recrystallize), but is well established for unreinforced metals (e.g., Ref. (7)), and is particularly suited for the measurement of high dislocation densities. In what follows we present an exploration of the use of this technique for deformed particle reinforced metals.

\section{Experimental Procedures}

Materials used were aluminum (99.9995\% pure, Ultimet ${ }^{\mathrm{TM}}$ from Alcoa, PA), and alumina particles having diameters between 10 and $44 \mu \mathrm{m}$ ( $99.9 \%$ pure, from Atlantic Equipment Engineering), containing sodium, calcium and sulfur as main impurities. The ceramic powder was first suspended in ethanol and ultrasonically dispersed. The coarse fraction was then dried and soaked for about 12 hours in a $25 \%$ HF solution, in order to dissolve any impurities, especially silicates (which would contaminate the aluminum matrix with silicon). After thorough rinsing with distilled water and drying, the powder was packed in a graphite cylinder $6 \mathrm{~mm}$ in inside diameter, $11 \mathrm{~mm}$ in outside diameter and $35 \mathrm{~mm}$ in length. The cylinder was put in an alumina crucible $(99.8 \%$ pure, $12 \mathrm{~mm}$ inside diameter) which had been treated with HF in a similar manner as the alumina powder. The aluminum was then placed on top of the preform, and the crucible was heated under vacuum in an infiltration apparatus described elsewhere (8). The preform was isothermally infiltrated for 10 minutes at a temperature of $963 \mathrm{~K}$ under argon gas pressurized to $14 \mathrm{MPa}$. After brief depressurization required to move the sample onto a chill, the composite was directionally solidified under a pressure of $3.5 \mathrm{MPa}$.

A portion of the matrix from the infiltrated composite and a sample from metal solidified in the crucible above the composite were dissolved in Aqua Regia and analyzed by wet chemical techniques. Cylindrical samples $6 \mathrm{~mm}$ in diameter and 2.5 to $3.4 \mathrm{~mm}$ in thickness were cut from the infiltrated composite with a low-speed diamond blade. The samples were then annealed under vacuum at $783 \mathrm{~K}$ for 4 hours and furnace-cooled. Each sample was deformed in uniaxial compression between cemented carbide platens at a temperature of $195 \mathrm{~K}$ to a macroscopic true strain between $\varepsilon=-0.02$ and $\varepsilon=-0.43$, Table 1. No lubricant was used in the compression tests to avoid any contamination of the samples, since even a small amount of lubricant reacting with, or decomposing on, the sample can produce a spurious exothermic signal during the calorimetric measurement.

Calorimetric experiments were performed on a Differential Scanning Calorimeter (DSC 7, Perkin Elmer) under $99.999 \%$ pure argon at a heating rate of $20 \mathrm{~K} / \mathrm{min}$. Each sample was cycled at least three times between $293 \mathrm{~K}$ and $513 \mathrm{~K}$ for Samples 1 to 3, and $293 \mathrm{~K}$ and $823 \mathrm{~K}$ for Samples 4 and 5. The DSC was calibrated with indium and lead and the DSC reference sample was annealed $99.995 \%$ pure aluminum. Peak energies were integrated using DSC software. Metallographic preparation of samples was done by grinding on silicon carbide paper and polishing with diamond slurries $(15 \mu \mathrm{m}$ and $3 \mu \mathrm{m})$ and diamond paste $(1 \mu \mathrm{m})$. Final lapping was performed with a silica slurry. The volume fraction of reinforcement $V_{f}$ was determined from two micrographs of magnification 100 covering an area of $0.86 \mathrm{~mm}^{2}$ using automated image analysis. 


\section{Results and Discussion}

Chemical analysis indicated that the matrix was virtually free of the most likely contaminants after composite processing (Si: 16 and 73 ppm; Fe: 52 and 105 ppm; Cu: 20 and 13 ppm for the metal solidified in the crucible and the composite respectively). The matrix can therefore be considered approximately $99.98 \%$ pure. Metallographic examination of the samples, Fig. 1, revealed that they were fully infiltrated and that the distribution of alumina particles was uniform. The volume fraction of reinforcement $V_{f}$ was measured on Samples 3 and 5 , yielding respectively $V_{f}=0.484$ and $V_{f}=0.533$. Deformation in compression induced barreling of sample 4 and 5 , which was probably a result of the lack of lubrication between the sample and the compression platens. These samples furthermore exhibited between 10 and 20 radial cracks extending from the sample side surface to a depth of about $0.5 \mathrm{~mm}$. Micrographs of Samples 3 and 5 showed no evidence of internal matrix cracks and some occurrences of particle cracking, particularly in Sample 5 (Figs. 1 \& 2).

While some overall drift in the curves was observed, there was no significant difference in curve shape between second and the third heating cycles for any of the samples. By comparison of the second and the third heating curves, experimental error in the measurement of heat released by the matrix is estimated to be on the order of $0.1 \mathrm{~J} / \mathrm{g}$. Results from differential scanning calorimetry are summarized in Table 1. Samples 4 and 5, which were deformed to a true strain of about $\varepsilon=-0.42$, each exhibited one exothermic peak on their first cycle (Fig. 3), which was not found upon reheating. The maximum temperature of each peak was located respectively at $368 \mathrm{~K}$ and $361 \mathrm{~K}$. With an average alumina volume fraction of about $51 \%$, these peaks correspond to a stored energy in the matrix of the deformed composites of $1.1 \mathrm{~J} / \mathrm{g}$ and $2.2 \mathrm{~J} / \mathrm{g}$, respectively. These exothermic peaks cannot be explained as being a result of matrix oxidation at the cracks formed during deformation: elementary calculations of the required oxide thickness yield an unrealistically high value (over $30 \mathrm{~nm}$ ); furthermore it is not expected that the oxide would form rapidly near $360 \mathrm{~K}$. We therefore retain matrix recrystallization as a possible explanation for the peaks observed in Samples 4 and 5.

Humphreys $(3,13)$ has proposed that if the ratio of particle volume fraction to average particle size is above $0.1 \mu \mathrm{m}^{-1}$ and the particles are greater than $1 \mu \mathrm{m}$, these will accelerate matrix recrystallization kinetics in particle reinforced metals. This criterion is satisfied in the present composites. Furthermore, most (although not all (3)) particle-reinforced pure aluminum composites have exhibited accelerated recrystallization in comparison to the unreinforced matrix deformed analogously. Recrystallization of the present composites is therefore expected to be faster compared to identically deformed unreinforced $99.98 \%$ pure aluminum. It is known that deformed high purity aluminum exhibits several thermal

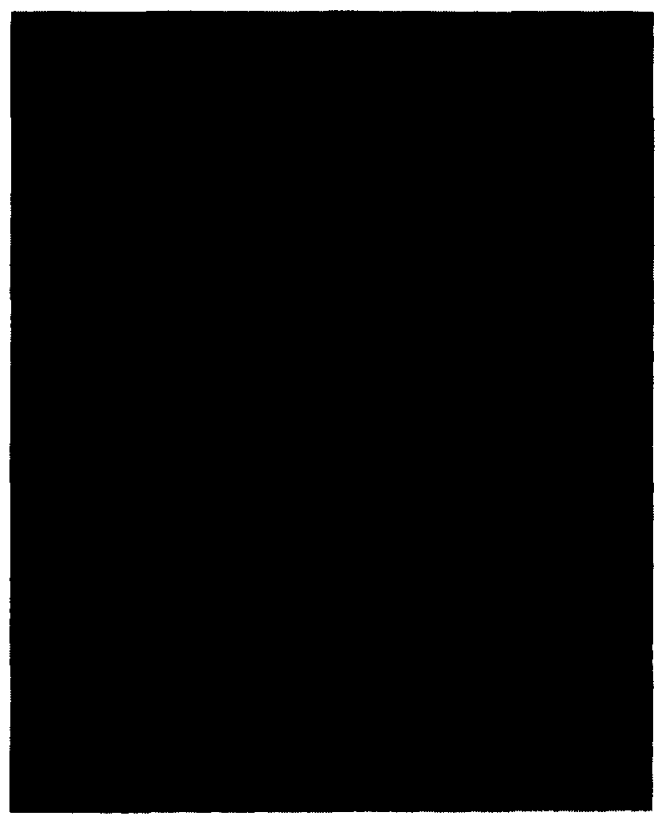

FIG.1 - Micrograph of deformed Sample 3.

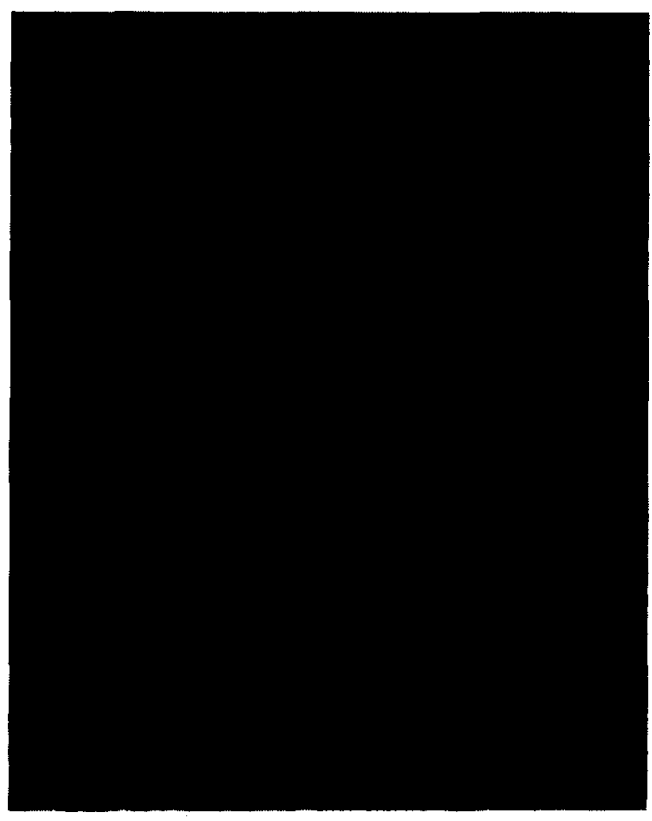

FIG.2 - Micrograph of deformed Sample 5. 

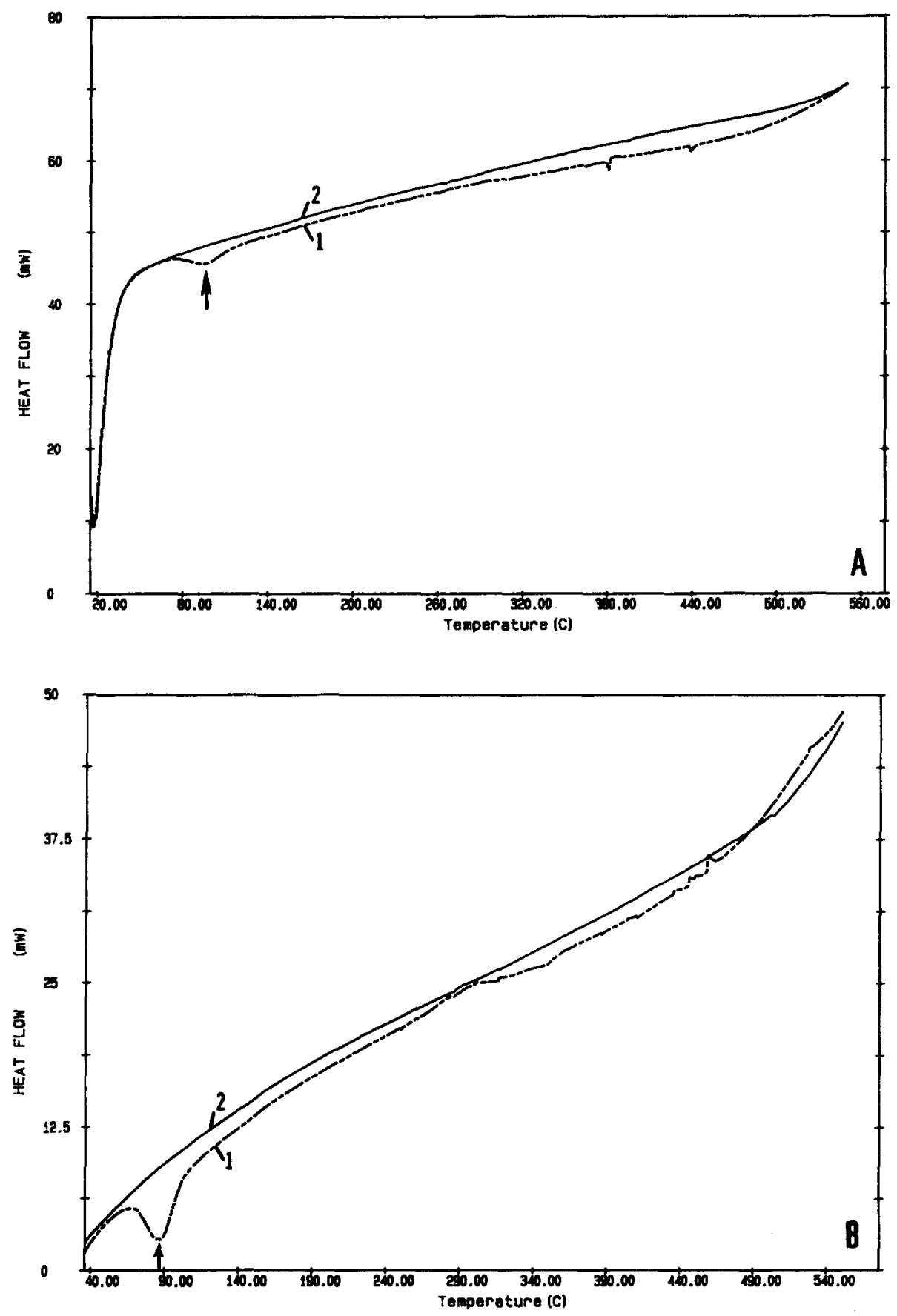

FIG. 3 - First (1) and second (2) DSC heating curves for Sample 4 (A) and S(B). 
TABLE 1 - Samples Strain, Peak Temperature and Released Energy.

\begin{tabular}{|c||c|c|c|}
\hline Sample & Compressive Strain & $\begin{array}{c}\text { Peak Temperature } \\
(\mathrm{K})\end{array}$ & $\begin{array}{c}\text { Peak Energy } \\
(\mathrm{J} / \mathrm{g})\end{array}$ \\
\hline \hline 1 & -0.02 & - & 0 \\
\hline 2 & -0.17 & - & 0 \\
\hline 3 & -0.25 & - & 0 \\
\hline 4 & -0.42 & 368 & 1.1 \\
\hline 5 & -0.43 & 361 & 2.2 \\
\hline
\end{tabular}

peaks upon annealing (7, 14-17). All but the highest-temperature peak frequently occur below room temperature and correspond to the annihilation of point defects by recovery. The highest-temperature peak corresponds to the annihilation of dislocations by primary recrystallization (15-17). Comparison with extensive data by Haeßner and Schmidt on high purity aluminum deformed by torsion between $77 \mathrm{~K}$ and $250 \mathrm{~K}(15-17)$ shows that, although conditions of deformation temperature and metal purity in the present study do not match precisely conditions explored by these authors, a recrystallization peak at about $365 \mathrm{~K}$ for $99.98 \%$ pure Al deformed at $200 \mathrm{~K}$ with a stored energy of the order of 1 to 2 $\mathrm{J} / \mathrm{g}$ is within the expected range. In summary, since we do not expect the particles to prevent recrystallization in our composites and since only one peak was observed up to $823 \mathrm{~K}$, we conclude that the peaks observed on Samples 4 and 5 correspond to annihilation of dislocations by primary recrystallization in the composites.

We note that because of the high ceramic particle volume fraction in the material and the high chemical purity of its matrix, grain boundary identification by conventional metallography is rendered difficult and was not attempted. We also note that comparison of the present data with published data on the recrystallization of particle or short whisker reinforced unalloyed aluminum is difficult since the matrix of the present samples is highly pure and free of submicron alumina dispersoids (introduced in powder processing), which are known to interfere with matrix recrystallization (9-12).

Many expressions have been proposed to link dislocation density with stored energy in deformed metals (7). In metal matrix composites, internal stresses, which are often present within the unloaded composite after plastic deformation due to unequal load partition between matrix and reinforcement and to inhomogeneity in plastic deformation of the matrix (18), may also contribute to the stored energy of cold work. We therefore consider two bounds for the matrix dislocation density that can be derived from the energy released by the deformed samples.

Transmission electron microscopy has shown that dislocations are arranged in cells in both as-processed and deformed high-purity aluminum reinforced with alumina fibers (5). If we assume that residual stresses in the composite are negligible, we can use Kuhlmann-Wilsdorf's equation for the volumetric energy of dislocations in cell walls (7, 19, 20):

$$
\Delta E \approx-\frac{\mu \cdot b^{2}}{4 \cdot \pi}\left[\rho_{\max } \cdot \ln \left(b \cdot \sqrt{\rho_{\max }}\right)\right]
$$

to deduce an upper bound for the density of dislocations in the deformed sample, Pmax, from the energy $\triangle \mathrm{E}$ released during recrystallization of the matrix. The shear modulus of aluminum is $\mu=23 \mathrm{GPa}$ and the Burgers vector of aluminum is $b=0.286 \mathrm{~nm}$. Inserting into $\mathrm{Eq}$. (1) the experimental value of stored energy gives $\rho_{\max }=6.4 \cdot 10^{15} \mathrm{~m}^{-2}$ for Samples 4 and $\rho_{\max }=1.4 \cdot 10^{16} \mathrm{~m}^{-2}$ for Sample 5 .

A lower bound for the dislocation density in the matrix, $\rho_{\min }$, can be estimated if we assume that the average residual stress in the matrix after unloading of the composite, $\left\langle\sigma_{\mathrm{m}}\right\rangle$, is equal to its flow stress $\sigma_{\mathrm{y}}$, estimated from:

$$
\sigma_{y}=\sigma_{0}+\alpha \cdot \mu \cdot b \cdot \sqrt{\rho}
$$

where $\alpha=0.5$ and $\sigma_{0}$ is negligibly small for high purity aluminum (21). Considering the extreme case in which the residual stress is hydrostatic in both phases, the reinforcement internal stress can be estimated from stress equilibrium as $<\rho_{p}=-\left(1-V_{f}\right)\left(V_{f}\right)^{-1}<\sigma_{m}>$. Assuming that, in the matrix, the elastic energy due to dislocation arrays and that due to the mean matrix stress can be added since the dislocations are concentrated at cell walls, $\rho_{\min }$ is found by adding the elastic stored energy due to residual stresses ( $\angle \sigma_{i}>2 / 2 K_{i}$ in phase $i$, where $K_{i}$ is the bulk modulus) to that due to dislocations in Eq. (1):

$$
\Delta E \approx \rho_{\min } \frac{\mu \cdot b^{2}}{4 \cdot \pi}\left[2 \cdot \pi \cdot \mu \cdot \alpha^{2}\left[\frac{1-V_{f}}{K_{m}}+\frac{\left(1-V_{f}\right)^{2}}{V_{f} K_{f}}\right]-\ln \left(b \cdot \sqrt{\rho_{\min }}\right)\right]
$$


where $K_{m}=73$ GPa and $K_{f}=245$ GPa. Eq. (3) yields $\rho_{\min }=5 \cdot 10^{15} \mathrm{~m}^{-2}$ for Samples 4 and $\rho_{\min }=1.2 \cdot 10^{16} \mathrm{~m}^{-2}$ for Sample 5. The two bounds for dislocation densities given by Eqs. (2) and (3) thus do not differ significantly in the present experiments.

Samples 1 to 3 exhibited no peak on initial heating after deformation, Fig. 4. Because, as mentioned above, the measured curve position shifted somewhat from cycle to cycle, any stored energies released gradually during heating (e.g., by recovery) could not be determined by subtraction of the second from the first heat-flux curves. The data nonetheless show that dislocation densities were lower in these samples, because a clear recrystallization peak was not observed, indicating that the energy released by recrystallization was lower than the experimental error of about $0.1 \mathrm{~J} / \mathrm{g}$. According to Eq. (1), this corresponds to $\rho_{\max } \leq 510^{14} \mathrm{~m}^{-2}$ in Samples 1 to 3 .

The energy released by Samples 4 and 5 is high: in HaeBner and Schmidt's experiments (17), 1 to $2 \mathrm{~J} / \mathrm{g}$ were stored by samples of $99.99 \%$ pure Al deformed in torsion to a shear strain of about 5 at $77 \mathrm{~K}$, while at $253 \mathrm{~K}$, shear in torsion of $99.999 \%$ pure Al resulted in a stored energy of only $0.44 \mathrm{~J} / \mathrm{g}$ at a torsion strain of 5.65 . The alumina particles thus produce a large enhancement in the rate of stored energy accumulation by aluminum during plastic deformation. Corresponding calculated stored dislocation densities also exceed significantly the geometrically-necessary dislocation density for compatibility of matrix plastic deformation, assuming negligibly small elastic deformation in the particles. This can be shown by assuming that equal numbers of prismatic and vacancy loops of length $4 \mathrm{~d}$ are punched into the matrix by particles of average diameter d. According to this simple model, the geometrically necessary dislocation density $\rho$ in the matrix is for a compressive strain $\varepsilon$ :

$$
\rho=\frac{8 \cdot|\varepsilon| \cdot V_{f}}{d \cdot b \cdot\left(1-V_{f}\right)}
$$

In Samples 4 and $5, \varepsilon$ is on the order of -0.42 . If a median value $d \approx 20 \mu \mathrm{m}$ is taken, Eq. (4) yields $\rho \approx 6.10^{14} \mathrm{~m}^{-2}$, significantly lower than dislocation densities calculated from measured values of the energy released by Samples 4 and 5 . We propose two possible mechanisms responsible for the greater dislocation densities measured in these samples. First, we note that punched dislocation densities exceeding those predicted by simple geometric models have been found to result from (much smaller) thermal mismatch strains in annealed or as-cast reinforced aluminum of varying purity (10, 11 , 22-25). Similar factors could have amplified the rate of dislocation creation and multiplication during compressive straining of the present composites. Secondly, we note that deformation of Samples 4 and 5 was inhomogeneous, indicative of significant friction between the platens and the sample. It is known that friction in compression testing

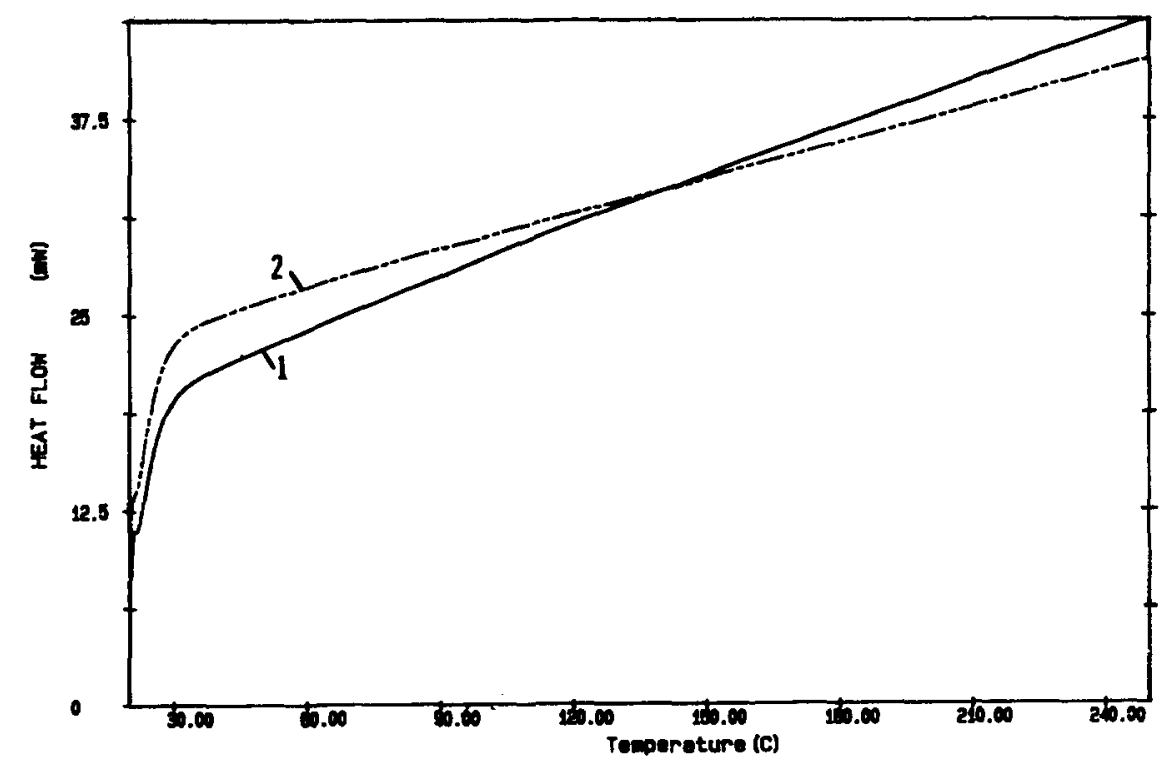

FIG. 4 - First (1) and second (2) DSC heating curves for Sample 3. 
produces hydrostatic compressive stresses at the center of the sample, particularly in samples of relatively low height-towidth ratios (which equaled about $1 / 2$ in the present study): in dry elastic friction, these stresses increase rapidly with increasing material flow stress and sample width (26). It is also known that hydrostatic compressive stresses produce sharp increases in punched dislocation densities within particle reinforced aluminum alloys which, in turn, increase the yield stress of the composite (27). It is possible, therefore, that stress triaxiality produced by friction along the compression platens enhanced the rate of dislocation accumulation in the matrix at the center of the strained samples. Unlike the former mechanism, which should produce a roughly constant rate of dislocation accumulation with strain, this mechanism would amplify rapidly the rate of dislocation accumulation as the sample widens and work hardens, which may explain the lack of signal in Samples 1 to 3.

In conclusion, we show that differential scanning calorimetry is a viable technique for the measurement of stored energy of cold-work in reinforced metals of high purity, provided a clear recrystallization peak is observed and stored energies are relatively high. We find that very high dislocation densities can be stored in particle-reinforced aluminum deformed in unlubricated compression to strains above about $40 \%$.

Acknowledgments: This work was sponsored by the Office of Naval Research, ONR \# NO0014-89-J-1541 under the supervision of Dr. Steven Fishman, with additional support for D.C.D. from the Swiss National Foundation.

\section{References}

1. J.P. Hirth et al., Scripta Metall. Mater. 25, 1-38 (1991).

2. R.J. Arsenault and R.M. Fisher, Scripta Metall. 17, 67-71 (1983).

3. F.J. Humphreys: in 9th Risф International Symposium on Metallurgy and Materials Science, S.I. Andersen, H. Lilholt, and O.B. Pedersen, ed., Risø National Laboratory, Roskilde, Denmark, 1988, pp. 51-74.

4. S.M. Pickard and B. Derby, Acta Metall. Mater. 38, 2537-2552 (1990).

5. J.A. Isaacs and A. Mortensen, Metall. Trans. 23A, 1207-1219 (1992).

6. P.B. Hirsch, A. Howie, R.B. Nicholson, D.W. Pashley, and M.J. Whelan, Electron Microscopy of Thin Crystals, Robert E. Krieger Publishing Co., Huntington, N.Y. (1977), pp. 422-424.

7. M.B. Bever, D.L. Holt, and A.L. Titchener: in Progress in Materials Science, B. Chalmers, J.W. Christian, and T.B. Massalski ed., Pergamon Press, Oxford, England, 1973, pp. 1 - 190.

8. J.A. Isaacs, F. Taricco, V.J. Michaud, and A. Mortensen, Metall. Trans. 22A, 2855-2862 (1991).

9. F.J. Humphreys, W.S. Miller, and M.R. Djazeb, Mater. Sci. and Technol. 6, 1157-1166 (1990).

10. C.Y. Barlow and N. Hansen, Acta Metall. Mater. 39, 1971-1979 (1991).

11. Y.L. Liu, N. Hansen, and D.J. Jensen, Metall. Trans. 20A, 1743-1753 (1989).

12. Y.L. Liu, D.J. Jensen, and N. Hansen, Metall. Trans. 23A, 807-819 (1992).

13. F.J. Humphreys, Metal Sci. 13, 136-145 (1979).

14. N.H. Andersen and D.J. Jensen: in Microstructural Characterization of Material by Non-Microscopical Techniques, N.H. Andersen et al., ed., Risø National Laboratory, Roskilde, Denmark, 1984, pp. 181-186.

15. F. Haeßner and J. Schmidt, Scripta Metall. 22, 1917-1922 (1988).

16. F. HaeBner: in Recrystallization '90, T. Chandra, ed., TMS/AIME, Warrendale, PA, 1990, pp. 511-516.

17. F. Haeßner and J. Schmidt, Acta Metall. Mater. 41, 1739-1749 (1993).

18. M.A.M. Bourke, J.A. Goldstone, M.G. Stout, and A. Needleman, in: Fundamentals of Metal Matrix Composites, S. Suresh, A. Mortensen, and A. Needleman ed., Butterworth-Heinemann, Stoneham, Mass., 1993, pp. 61-80.

19. D. Kuhlman-Wilsdorf and J.H. vander Merwe, Mater. Sci. Eng. 55, 79-83 (1982).

20. D. Kuhlman-Wilsdorf: in Work Hardening, J.P. Hirth and J. Weertman, ed., Gordon \& Breach, New York, 1966, pp. 97-139.

21. P. Guyot and G.M. Raynaud, Acta Metall. et Mater. 39, 217-322 (1991).

22. R.J. Arsenault and C.S. Pande, Scripta Metall. 22, 767-772 (1988).

23. R.J. Arsenault, L. Wang, and C.R. Feng, Acta Metall. Mater. 39, 47-57 (1991).

24. F. Rézai-Aria, T. Liechti, and G. Gagnon, Scripta Metall. Mater. 28, 587-592 (1993).

25. J.A. Isaacs and A. Mortensen: in 12th Ris $\phi$ International Symposium on Metallurgy and Materials Science: Metal Matrix Composites-Processing, Microstructure and Properties, N. Hansen et al. ed., Ris $\varnothing$ National Laboratory, Roskilde, Denmark, 1991, pp. 399-404.

26. W.A. Backofen: Deformation Processing, Addison Wesley, Reading, Mass, 1972, pp. 162-168.

27. J.J. Lewandowski, D.S. Liu, and C. Liu, Scripta Metall. Mater. 25, 21-26 (1991). 